have a good sleep to feel rested. Health as independence meant to have both physical and financial prerequisites to perform everyday activities, to exercise and being able to travel. Health as life satisfaction meant to feel joy in life, enjoy the family and to believe in the future. Health as vitality meant to have the energy, power and strength to cope with everyday life. The patients expressed that their health had been adversely affected by the RA disease and they had a strong desire for full health including well-being, independence, life satisfaction and vitality.

Conclusions: Patients in an early stage of RA describe a strong desire to regain health in terms of well-being, independence, life satisfaction and vitality. The concept of health at early RA is similar to health at established RA in terms of wellbeing, independence and life satisfaction. Unique findings for patients with early RA are the description of health as vitality, and the emphasis of having energy, power and strength to cope with everyday life. Health professionals should have these different ways of experiencing health in mind when providing person-centred care to patients with early RA. Depending on the patients' perception of health, different support strategies are needed.

Disclosure of Interest: None declared

DOI: 10.1136/annrheumdis-2018-eular.3305

\section{FRI0708-HPR THE USE OF TECHNOLOGY FOR SYMPTOM MEASUREMENT IN RHEUMATOID ARTHRITIS: A QUALITATIVE INVESTIGATION}

F. Matcham ${ }^{1}$, R. Williams ${ }^{2}$, E. Foncel ${ }^{3}$, H.-Y. Tung ${ }^{4}$, S. Norton ${ }^{5}$, J. Galloway ${ }^{3}$, M. Hotopf ${ }^{6} .{ }^{1}$ Department of Psychological Medicine, IoPPN, King's College London; ${ }^{2}$ Department of Rheumatology, Faculty of Life Sciences \& Medicine, King's College London; ${ }^{3}$ Department of Rheumatology, Faculty of Life Sciences \& Medicine, King's College London; ${ }^{4}$ Psychology Department, nstitute of Psychiatry, Psychology \& Neuroscience, King's College London; ${ }^{5}$ Psychology Department; ${ }^{6}$ Department of Psychological Medicine, Institute of Psychiatry, Psychology \& Neuroscience, King's College London, London, United Kingdom

Background: Rheumatoid Arthritis (RA) outcome measurement is limited by infrequent appointments, triggered by symptom flares, linking blood test data with retrospective recall of symptoms. Remote measurement technologies (RMT), such as wearable sensors or smartphone apps, provide opportunity for ongoing measurement of symptoms such as pain, fatigue, and depression, which may vary throughout the day, offering new insight into the lived experience of chronic illness [1]. However, implementation of such data collection strategies requires careful development with the service-user an integral part of co-design to maximise real-world acceptability [2]

Objectives: This study aimed to gather qualitative information about serviceuser priorities for using RMT for symptom measurement.

Methods: Two focus groups were conducted in people with RA, using a semistructured topic guide designed to elicit thoughts about RA symptoms considered important and acceptable for measurement via RMT. The focus groups were moderated by an expert service user (RW) and research lead (FM). A systematic thematic analysis was applied to the data, using a coding framework to extract themes and sub-themes by two researchers independently.

Results: A total of 9 participants attended the two focus groups. Participants were aged 23-77 (mean=55.8, SD=18.1), with a mean disease duration of 20.2 $(S D=15.2)$. All 9 were female, with $44.4 \%$ identifying as White British. Symptoms prioritisations and the perceived benefits and risks of technology were categorised into several themes including: personal empowerment; communication with healthcare teams; routine/convenience; and under-prioritised symptom experiences.

Conclusions: The results of these focus groups highlight several areas to focus RMT development in this area, including identifying the symptoms patients feel are under-prioritised by healthcare providers, and establishing methods to ensure RMT can be embedded in daily activities despite fluctuating symptom severity. Future work testing specific app prototypes and wearable usability can ensure RMT projects are developed with optimised user experience.

\section{REFERENCES:}

1. Lee YG, Jeong WS, Yoon G. Smartphone-based mobile health monitoring Telemedicine and E-Health 2012;18:585-90.

2. Grainger R, Townsley H, White B, Langlotz T, Taylor WJ. Apps for people with rheumatoid arthritis to monitor their disease activity: A review of app for best practice and quality. JMIR mHealth and uHealth 2017;2:e7.

Acknowledgements: We thank Radka Chura for her assistance with recruitment and all participants for their contribution.

Disclosure of Interest: None declared

DOI: 10.1136/annrheumdis-2018-eular.3491

\section{FRI0709-HPR LEVELS OF SATISFACTION WITH PSORIATIC ARTHRITIS (PSA) TREATMENT AND ASSOCIATED ALIGNMENT BETWEEN RHEUMATOLOGISTS AND} THEIR PATIENTS ACROSS LATIN AMERICA

F. Zazzetti ${ }^{1}$, E.R. Soriano ${ }^{2}$, D. Rocio Gil ${ }^{3}$, J. Maldonado $\operatorname{cocco}^{4}$, D. Vega Morales ${ }^{5}$ I. Alves Pereira ${ }^{6}$, G. Guerra ${ }^{7}$, W. Bautista Molano ${ }^{8}$, J.C. Cassola ${ }^{9}$, V. Azevedo ${ }^{10}$, L M. Aldunate 1 , S. Lobosco ${ }^{11}$. ${ }^{1}$ Medical Affairs, JANSSEN; ${ }^{2}$ Rheumatology Section, Hospital Italiano Buenos Aires, buenos aires, Argentina; ${ }^{3}$ Rheumatology, Hospital Universitario Mayor MEDERI, Bogota, Colombia; ${ }^{4}$ Rheumatology, Buenos Aires University School of Medicine, Buenos Aires, Argentina; ${ }^{5}$ Rheumatology, Hospital Universitario "Dr. José Eleuterio González", Monterrey, Mexico; ${ }^{6}$ Rheumatology, Universidade Federal de Santa Catarina, Hospital Universitário, Florianopolis, Brazil; ${ }^{7}$ Rheumatology Section, Centro Médico Paitilla, panama, Panama; ${ }^{8}$ Rheumatology, Universidad Militar Nueva Granada and Rheumatology Department, Hospital Militar, Bogota, Colombia; ${ }^{9}$ Rheumatology Section, Hospital General de México, ciudad de Mexico, Mexico, Mexico; ${ }^{10}$ Rheumatology, University of Paraná; Brazil, Parana, Brazil; ${ }^{11}$ Rheumatology, Adelphi Group, Manchester, UK

Objectives: To assess levels of rheumatologist and patient satisfaction with PsA treatment across Latin America and any disconnects that may exist between the two in real world clinical practice.

Methods: Data from the 2015 PsA Disease Specific Programme (DSP), a crosssectional, multi-national survey of patients and rheumatologists conducted in Argentina, Mexico, Colombia and Venezuela were analyzed. Rheumatologists ( $n=141)$ completed forms containing patient demographics, patient disease severity and treatment satisfaction. Patients self-reported their level of treatment satisfaction and disease severity.

Results: A total of 293 PsA patients from across Latin America were included in this analysis. Current mean age was 49.9 years and $48.1 \%$ were female. Proportions of rheumatologists and patients reporting satisfaction with treatment were both similarly high ( $84 \%$ and $92 \%$ respectively), however current disease severity reporting differed more markedly between rheumatologists and patients (mild $78 \% /$ moderate-severe $22 \%$ rheumatologists vs. $63 \%$ mild $/ 37 \%$ moderate-severe patients; $p=0.002$ ). When assessed for alignment, $19 \%$ of all rheumatologists and patients disagreed on the level of treatment satisfaction; $13 \%$ of this was due to rheumatologists stating greater dissatisfaction than their patients, with the remaining $6 \%$ due to patients stating greater dissatisfaction than their rheumatologists $(p=0.0543)$. For current disease severity, $32 \%$ of all rheumatologists and patients disagreed; $25 \%$ due to patients stating greater severity than their rheumatologists with $7 \%$ due to rheumatologists stating greater severity than their patients $(p<0.001)$. Of those patients for whom their rheumatologist was satisfied with treatment, $14 \%$ were classified as having moderate to severe PsA by that same physician.

Conclusions: Despite many rheumatologists and their patients in Latin America reporting high levels of satisfaction with treatment, PsA patients can remain moderate to severe and disconnected from their physician. There is a need to improve physician/patient engagement as a means to improving clinical control.

Disclosure of Interest: None declared

DOI: 10.1136/annrheumdis-2018-eular.5597

\section{FRI0710-HPR OBJECTIVE AND SUBJECTIVE MEASURES OF PHYSICAL FUNCTIONING IN WOMEN WITH FIBROMYALGIA: WHAT TYPE OF MEASURE IS ASSOCIATED MOST CLEARLY WITH SUBJECTIVE WELL-BEING? THE AL-ÁNDALUS PROJECT}

F. Estevez-Lopez ${ }^{1,2}$, F.M. Acosta ${ }^{1}$, P. Acosta-Manzano ${ }^{1}$, M. Rodriguez-Ayllon ${ }^{1}$, B. Gavilán-Carrera' ${ }^{1}$, M. Herrador-Colmenero ${ }^{1}$, A. Carbonell-Baeza ${ }^{3}$, R. Geenen $^{2}$, B. Walitt ${ }^{4}$ D. Munguía-Izquierdo ${ }^{5}$, M. Pulido-Martos ${ }^{6} .{ }^{1}$ University of Granada, Granada, Spain; ${ }^{2}$ Utrecht University, Utrecht, Netherlands; ${ }^{3}$ University of Cádiz, Cádiz, Spain; ${ }^{4}$ National Institute of Nursing Research, National Institutes of Health, Bethesda, MD, United States; ${ }^{5}$ Universidad Pablo de Olavide, Seville; ${ }^{6}$ University of Jaén, Jaén, Spain

Background: In fibromyalgia there is a discordance between performancebased (i.e., objective) and patient-reported (i.e., subjective) physical functioning $(1,2)$. However, it is unknown whether the association of physical functioning with health outcomes is different between objective and subjective measures.

Objectives: To analyse the associations of the objective and subjective dimensions of physical activity, sedentary behaviour, and physical fitness with subjective well-being in women with fibromyalgia.

Methods: This population-based cross-sectional study included 375 women with fibromyalgia from southern Spain. Physical activity, sedentary behaviour, and physical fitness were measured by questionnaires, accelerometers, and performance testing. Participants self-reported their levels of positive affect, negative affect, and satisfaction with life. Conservative multivariate analyses were used to 
analyse the association between these physical functioning measures and the assessment of affect and life satisfaction.

Results: We found independent associations of the objective measures but not the subjective assessments of physical activity with positive affect and satisfaction with life (both, $p<0.01$ and adjusted $R^{2}>0.06$ ) and of sedentary time with positive affect ( $p<0.02$ and adjusted $R^{2}>0.03$ ). Moreover, we observed consistent and independent associations of both the objective and subjective dimensions of physical fitness with all the components of subjective well-being (all, $p<0.01$ and adjusted $R^{2}$ ranged from 0.02 to 0.05 ).

Conclusions: Both objective and subjective measures of physical activity and sedentary behaviour independently impact affect and subjective well-being. Strategies to enhance both dimensions of physical fitness may be a promising approach for improving the subjective well-being in fibromyalgia.

\section{REFERENCES:}

1. Estévez-López F, et al. Disabil Rehabil 2018;40(3):329-337.

2. Estévez-López F, et al. Rheumatology (Oxford) 2017;56(11):2015-2024.

Acknowledgements: This study was funded by the Spanish Ministries of Economy and Competitiveness [I+D+I DEP2013-40908-R, I+D+I DEP2010-15639, BES-2014-067612] and Education [FPU15/00002]

Disclosure of Interest: None declared

DOI: 10.1136/annrheumdis-2018-eular.6370

\section{FRI0711-HPR KINESIOPHOBIA IN ADULT PATIENTS WITH FAMILIAL MEDITERRANEAN FEVER: ASSOCIATION WITH PHYSICAL ACTIVITY, DEPRESSION AND ANXIETY}

I. Karanki, E.I. Günaydın, A. Çetinkaya, S. Saka, M.G. Yavuzer. Haliç University, Istanbul, Turkey

Background: Familial Mediterranean fever (FMF) characterized by pain and inflammation with fever which requires a lifelong treatment ${ }^{1}$. All of this causes psychosocial influences and also causes kinesiophobia, which is defined as avoidance of physical activity and fear of repetition of the pain. As it may affect the levels of physical activity and functional capacity, it is important to identify factors related to kinesiophobia in patients with FMF.

Objectives: The aim of this study was to investigate the existence of kinesiophobia and related factors such as depression, anxiety and physical activity in adult patients with FMF.

Methods: 38 subjects with FMF (15 male) from Society of Behçet \& FMF Diseases included in the study. The demographic characteristics of the participants were recorded. The 'Tampa Scale for Kinesiophobia (TSK)', 'International Physical Activity Questionnaire (IPAQ)', 'Hospital Anxiety and Depression Scale $(\mathrm{HADS})^{4}$ ' and 'Fatigue Severity Scale (FSS) ${ }^{5}$ ' were used to assess associated factors.

Results: Demographic and disease characteristics of the participants were presented in the table 1 . Only 9 subjects reported regular exercise. $86 \%$ of the subjects had a score over 37 in TSK representing high kinesiophobia ${ }^{6}$. TSK scores were positively correlated with HAD-D $(r=0,530 ; p=0,001)$ and FSS $(r=0,340$; $p=0,035$ ). On the other hand, age, disease duration, body mass index, HAD-A and IPAQ scores were not correlated with TSK. Gender or exercise routine had no effect on TKS.

Table 1 Demographic and disease characteristics

\begin{tabular}{llll}
\hline & Mean \pm Std & Min. & Max. \\
\hline $\begin{array}{l}\text { Age (year) } \\
\text { Disease duration } \\
\text { (years) }\end{array}$ & $37.05 \pm 8.71$ & 19 & 57 \\
BMI $\left(\mathrm{kg} / \mathrm{cm}^{2}\right)$ & $13.11 \pm 11.14$ & 1 & 46 \\
IPAQ & $24.5 \pm 4.43$ & 16.65 & 38.05 \\
& 6942.5 & 3018 & 14580 \\
TSK & \pm 2520.4 & & \\
HAD-A & $44.16 \pm 5.06$ & 33 & 54 \\
HAD-D & $9.84 \pm 4.43$ & 2 & 20 \\
FSS & $8.82 \pm 4.70$ & 1 & 20 \\
\hline
\end{tabular}

Conclusions: Kinesiophobia is very common and associated with depression and fatigue in patients with FMF. Limited number of participants reported regular exercise habit which should be added to treatment programs to increase physical activity and functional capacity in patients with FMF.

\section{REFERENCES}

1. Makay, Emiroğlu N, Unsal E. Depression and anxiety in children and adolescents with familial Mediterranean fever. Clin Rheumatol 2010 Apr;29 (4):375-9.

2. Yılmaz OT, Yakut Y, Uygur F, Uluğ N. Turkish version of the Tampa Scale for Kinesiophobia and its test-retest reliability Fizyoterapi Rehabilitasyon $2011 ; 22(1): 44-49$.

3. Sağlam M, Arıkan H, Savcı S, Inal-Ince D, Boşnak-Güçlü M, Karabulut $E$, et al. International physical activity questionnaire: reliability and validity of the Turkish version. Perceptual and motor skills 2010;111(1):278-84.

4. Aydemir O, Güvenir T, Küey L, Kültür S. Reliability and Validity of the Turkish version of Hospital Anxiety and Depression Scale. Turkish journal of psychiatry 1997;8(4):280-287.

5. Armutlu K, Korkmaz NC, Keser I, Sumbuloglu V, Akbiyik DI, Guney Z, Karabudak R. The validity and reliability of the Fatigue Severity Scale in Turkish multiple sclerosis patients. Int J Rehabil Res. 2007 Mar;30(1):81-5.

6. Vlaeyen J, Kole-Snijders AMJ, Rotteveel AM, Ruesnik R, Heuts PHTG The role of fear of movement((re)injury in pain disability. J Occup Rehab 1995;5(4):235-51.

Disclosure of Interest: None declared

DOI: 10.1136/annrheumdis-2018-eular.3695

\section{FRI0712-HPR THE EXPERIENCE OF PATIENTS WITH DIFFERENT CHRONIC DISEASES WITH HEALTH CARE. A SURVEY WITH THE IEXPAC INSTRUMENT}

J. de Toro ${ }^{1}$, L. Cea-Calvo ${ }^{2}$, M.L. García-Vivar ${ }^{3}$, L. Pantoja ${ }^{4}$, C. Lerín ${ }^{5}$, S. GarcíaDíaz $^{6}$, M.J. Galindo ${ }^{7}$, I. Marín-Jiménez ${ }^{8}$, M. Mosquera ${ }^{2}$, M.J. Arteaga ${ }^{2}$, D. OrozcoBeltrán ${ }^{9} .{ }^{1}$ Rheumatology Department, H. U. A Coruña, Universidad A Coruña, INIBIC, A Coruña; ${ }^{2}$ Merck Sharp \& Dohme, Madrid; ${ }^{3}$ Rheumatology Department, Basurto University Hospital, Bilbao; ${ }^{4}$ Rheumatology Department, H. El Bierzo, Ponferrada; ${ }^{5}$ Rheumatology Department, Manacor Hospital, Palma de Mallorca; ${ }^{6}$ Rheumatology Department, Moisés Broggi Hospital, Barcelona; ${ }^{7}$ Internal Medicine Department, H. Clínico de Valencia, Valencia; ${ }^{8}$ Gastroenterology Department, $H$. U. Gregorio Marañón, Madrid; ${ }^{9}$ Department of Medicine, Miguel Hernández University, Sant Joan, Alicante, Spain

Background: Insights from patients are important for health care planning Objectives: In this study we describe the perception of patients with 4 different chronic conditions with health care in Spain through the IEXPAC scale ("Instrument to Evaluate the EXperience of PAtients with Chronic diseases"), a scale developed and validated in Spain.

Methods: The IEXPAC scale (http://www.iemac.es/iexpac/) was developed and validated in Spain by health care professional and social organizations, experts in quality of health care and chronic patients. The scale is structured in 12 items with Likert responses from "always" to "never", yields a score from 0 (worst experience) to 10 (best experience), and identifies aspects of health care needing improvement. A survey was handed to patients needing care in at least two different levels (i.e. primary care and hospital) and with one of the following chronic conditions A) Rheumatic diseases, B) Inflammatory bowel disease (IBD), C) Human immunodeficiency virus infection (HIV) and D) Diabetes mellitus (DM) plus cardiovascular or renal chronic disease. Patients completed the survey at home and responded by pre-paid mail.

Results: 2474 patients received the survey, $1618(65.4 \%)$ returned it (359 with rheumatic disease, 341 with IBD, 467 with HIV infection, 451 with DM, mean age 56 years, $41 \%$ women). Only $6.1 \%$ were affiliated to a patients association. Patients declared a median of 8 visits (IQR 25-75: 4-15) to primary care or specialty clinics in the last year and $29 \%$ had visited an emergency room. In the last 3 years $48 \%$ had been hospitalized. Up to $61 \%$ reported to search for information on diseases, therapies, lifestyle or diet in webpages, general or social media. Responses to the IEXPAC items (percentages that responded "mostly" + "always" to each item) are displayed in the table. In general, these \% were higher in HIV patients, which represents a better experience with health care. In some items, patients with rheumatic diseases scored lower (table 1). Mean IEXPAC score was 6.0 (SD1.8) and was higher in HIV patients (table 1). Worst scores were seen in items related to access or guidance for getting reliable information on health and on social resources, contact with other patients and follow-up after hospital discharge. 